WellBeing International

WBI Studies Repository

2001

\title{
Animal Suffering: An Invertebrate Perspective
}

Jennifer A. Mather

University of Lethbridge

Follow this and additional works at: https://www.wellbeingintlstudiesrepository.org/acwp_asie

Part of the Animal Studies Commons, Comparative Psychology Commons, and the Other Animal Sciences Commons

\section{Recommended Citation}

Mather, J. A. (2001). Animal suffering: An invertebrate perspective. Journal of Applied Animal Welfare Science, 4(2), 151-156.

This material is brought to you for free and open access by WellBeing International. It has been accepted for inclusion by an authorized administrator of the WBI Studies Repository. For more information, please contact wbisr-info@wellbeingintl.org.

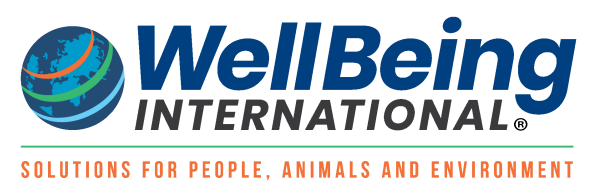




\title{
Animal Suffering: An Invertebrate Perspective
}

\author{
Jennifer A. Mather \\ The University of Lethbridge
}

\begin{abstract}
Consideration of the welfare of other animals often is anthropocentric, focusing usually on mammals similar to humans. This article argues the necessity of evaluating the extension of such consideration more widely to invertebrates. Although unlike humans, some groups such as cephalopod molluscs probably have the potential for pain and suffering. In addition, a morality of care, rather than one of rights, and the damage humans do to themselves by cruel treatment of animals both argue for the extension of consideration to all animal species. This consideration predicts extension of basic care of cephalopods from simple housing and feeding into areas such as behavioral enrichment.
\end{abstract}

When it comes to evaluating suffering of nonhuman animals or considering how to provide them with appropriate care, it can be argued that we humans are quite anthropocentric. Basically, and not surprising, we see the world in terms of us. We have a complex series of regulations that control our management of research animals (Olfert, Cross,\& McWilliam, 1993), but it is nearly all about vertebrates and, in particular, mammals. In the West, and particularly in science, we emphasize morality as rights and justice (Hinman, 1998) and extend consideration to animals similar to us. So where does that leave my octopuses? Certainly, they are nothing like us. In fact, they belong to a branch of the molluscs, the cephalopods, and are far more closely related to boring clams than to intelligent monkeys or cats. Yet, grounds for extending some ethical consideration to octopuses come from their well-known intelligence (Hanlon \& Messenger, 1996; Mather, 1996; Mather \& Anderson, 2000). Because they have the sensory ability, memory capacity, and range of responses expected of mammals, we tentatively extend some consideration of animal welfare to them (Olfert et al., 1993).

Another side to this problem of what animals to consider is the issue of which ones experience pain and suffering. Even students of human perception have trouble describing pain. Matlin and Foley (1997) referred to Merskey (1986), who, in a complex definition that probably covers all the bases, says that pain is "an unpleasant sensation associated with actual or potential tissue damage, or defined in terms of such damage" (p. 380). This reflects an understanding that pain is sensory but also cognitive and emotional.

Suffering also must include some aspect of awareness, understanding, and perhaps anticipation of pain. Scientists are unwilling to impute awareness without proof. Despite Griffin's (1992) heroic attempts over the years to ask scientists to assume animal awareness, mostly we do not. No proven awareness, no pain? There has been resurgence recently in scientific research on "self-awareness" of animals (Parker, Mitchell, \& Boccia, 1994). Although promising, it is anthropocentric, with 24 of 27 presentations in the book cited here discussing primates. 


\section{THAT LEAP OF FAITH}

Despite not knowing what they might feel, it is relatively easy for me to take a leap of faith and recognize the dog who cringes before punishment, the cats who scream in pain when their paws are crushed, and assume that they are in pain or suffering. It is much less easy for me to decide that one of my octopuses who recoils from contact with a sea anemone is hurting or that a lobster feels pain when being boiled. One way around this dilemma is to coin a new term, nociception (Kavaliers, 1988). It indicates the sensory aspect of unpleasant sensations resembling our pain, without presuming our subjective reactions and suffering. Still, we humans would be a bit hypocritical to separate ourselves too far from other animals. After all, the physiological systems that control responses to what we call pain mostly are universal across the animal kingdom, and snails often are used as models for such responses. Can we treat them as having sensations that resemble ours without being concerned for their welfare when they do?

Still, it is less easy to take that leap of faith and presume parallels with how you feel when the animal concerned is completely unlike you. Insects, for instance, can walk normally with a couple of broken-off legs and survive with apparent unconcern as a parasite is eating them up inside, when presumably we would be in excruciating pain. Does that mean they cannot feel pain? I asked a friend who works with ants what she thought about this apparent inability to feel the pain we do. She said that she spilled a drop of acetone on an ant by accident one day and that it had recoiled and tried to wipe the substance off its abdomen. Maybe it is still pain, just responding to different stimuli. Alternately, maybe it is an automatic grooming reaction. Because nuclear radiation can kill us without our feeling a thing, humans too do not always respond with pain to possible tissue destruction.

On the other hand, the arthropod nervous system has a series of ganglia down the back instead of our centralized brain. A male praying mantis trying to mate with a female may run afoul of her predatory drive. The female may reach out and chew the head off her mate, but this does not stop him. The control for mating apparently is located in an abdominal ganglion and continues; it even can be argued from an evolutionary viewpoint that the donation of his body as food helps foster development of his unborn young. So where is the location of any aversive reaction? Where, and with what, does the insect feel?

\section{PARALLELS BETWEEN VERTEBRATES AND THE OCTOPUS}

There are better parallels between vertebrates and the octopuses and squid on which I do research. They have a large and well-centralized nervous system, much of it condensed into what clearly can be described as a brain. Octopuses are known for their learning ability and behavioral flexibility, and their cognitive capacity is suspected to be well beyond what we have proven (Mather, 1996). Octopuses are repelled by a natural stimulus, the same sea anemones mentioned previously (as are humans to some species), and show every sign of nociception when stung by one. This ability transferred easily, and a series of learning experiments in Naples (Wells, 1978) used small electrical shocks effectively to induce their learning not to take a visual stimulus.

In addition to receiving unpleasant sensations, the octopuses showed every sign of calculating the whole situation and changing their behavior accordingly. Octopuses stung by a sea anemone protectively placed on the shell of a hermit crab do not just retreat. They may circle around, as if planning to attack the crab and anemone from the rear. They may climb up the side of an aquarium and reach an arm or two down around the anemone. One of the ones I tested sneaked-tiptoeing on arm suckers-along the aquarium bottom, getting close enough to grab the hermit crab without having to leap and encounter the anemone. Several enterprising octopuses aimed strong jets of water at the anemone, as if hoping to blow it off the shell. 
Octopuses caught in this or similar dilemmas show another response. They often change their skin color, sometimes to the pale color associated with fright and sometimes to a red we see inevitably as anger. We really do not know how to tell if octopuses have emotions, even when we see such reactions. Surely, something (Anderson, 2000) like an emotional as well as a cognitive reaction is going on in this situation. Evidence of aversion, signs of emotion-like responses, and cognitive ability to anticipate and avoid the situation all sound very much like the responses of "higher" vertebrates to threat and pain.

Because some invertebrates can suffer, does that mean we ought to assume that every animal is sentient, that we should give up on lobster dinner and steamed clams, become sensitive vegetarians, and let the mosquitoes bite? Admittedly, our being vegetarian would be good for the planet. However, most of us probably will not go as far as the Jains, who believe in taking no life (Jain, 1989)—but there are commonsense guidelines.

\section{THE BASICS OF SUFFERING}

First, suffering suggests a large and complex nervous system, and many invertebrates have no such complexity. Pain arguably is a signal for avoiding tissue damage and may have evolved only where behavioral complexity and learning are common. The basic five molluscan ganglia are centralized and augmented to form a cephalopod brain but in clams are spread widely and much reduced. Little nervous tissue is left to deal with complex sensations; the clams have a good life but a simple one, and even their ability to receive nociception is minimal. Giving your dog a worm pill probably does not cause the parasites expelled much suffering either, as their nervous systems are even more reduced. Olfert et al. (1993) took these different cases under advisement when evaluating extending Animal Care regulations to research on invertebrates. The regulations now read that because some invertebrates have welldeveloped nervous systems and respond to noxious stimuli, they must be treated humanely. Common sense comes into play, and Boyle (1991) outlined some of the procedures and cautions when working with cephalopods.

How do we know whether that lobster is suffering? What should we do? Some of the humane things we can do involve knowing what might be damaging and minimizing what we inflict on the animal. The lobster has a brain just behind the eyes. If concerned about suffering in the pot, you easily can destroy this before cooking. One of my cookbooks outlines how to do this, using a pin or knife (Peterson, 1999). Surely, we agree that lingering death is never pleasant, so whatever needs to be done to any animal should be done quickly. Research on how to enhance care of these animals so unlike us would be helpful. We could try to find out how they work by better accommodating, not ignoring, them.

\section{ETHICAL CONSIDERATIONS}

More than suffering of animals is involved in extending consideration to them, including invertebrates. In what might be described as an ethic of caring (Hinman, 1998), and as discussed in detail by Rollin (1985), consideration also is of value to its human givers. Systematic inflicting of what we assume to be pain and suffering on other beings (or seeing it happen) can make people callous. In particular, this is emphasized in abattoirs (Grandin, 1988) and animal care facilities, where abandoned companion animals may be euthanized (White \& Shawhan, 1996). With a renewed public emphasis on animal care, circus, zoo, and aquarium spectators also may demand high standards of care or complain when they see what they presume is cruelty.

One aspect of animal care touching directly on indirect suffering is the alleviation of boredom. Intelligent vertebrates such as monkeys and parrots often suffer from the restrictions captivity imposes on their natural behavior (Shepherdson, Mellen,\& Hutchins, 1998). Octopuses are highly exploratory and even 
play (Mather \& Anderson, 1999), but we do not know whether they suffer from the limitations of confinement. To prove that octopuses get bored, researchers would have to know that (a) octopuses are capable of boredom; (b) in confinement, they become negative and self-destructive; and (c) such behavior reverts when they are given enrichment. As yet, we do not know if they meet these conditions, but the obvious positive effects for animal keepers and the public has led to the enrichment attempts described in the following article (Anderson \& Wood, 2001/this issue).

Obviously, there is no simple answer about extending ethical consideration to invertebrate animals. Different vertebrate species have different physiologies and need different considerations. The invertebrates are a vastly more diverse group. Still, at least some invertebrates very likely have the capacity for pain and suffering and, perhaps, mental suffering. Thus, it is appropriate to extend ethical consideration to all animals in our care, fortunately not only because it is good for them but also because it is good for us.

\section{REFERENCES}

Anderson, R. C. (2000). Seeing red. In M. Bekoff (Ed.), The smile of the dolphin: Remarkable accountsof animal emotions (pp. 84-87). New York: Discovery Inc.

Anderson, R. C., \& Wood, J. B. (2001/this issue). Enrichment for Giant Pacific octopuses: Happy as a clam? Journal of Applied Animal Welfare Science, 4, 157-168.

Boyle, P. R. (1991). UFAW handbook on the care and management of cephalopods in the laboratory. Potter's Bar, England: Universities Federation for Animal Welfare.

Grandin, T. (1988). Behavior of slaughter plant and auction employees toward the animals. Anthrozoös, 1, 205-213.

Griffin, D. R. (1992). Animal minds. Chicago: University of Chicago Press.

Hanlon, R. T., \& Messenger, J. B. (1996). Cephalopod behaviour. Cambridge, England: Cambridge University Press.

Hinman, L. M. (1998). Ethics: A pluralistic approach to moral theory (2nd ed.). Toronto, Canada: Harcourt Brace.

Jain, P. S. (1989). The ethics of Jainism. In S. C. Crawford (Ed.), World religions and global ethics (pp. 65-88). New York: Paragon.

Kavaliers, M. (1988). Evolutionary and comparative aspects of nociception. Brain Research Bulletin, 21, 923-931.

Mather, J. A. (1996).Cognition in cephalopods. Advances in the Study of Behavior, 24, 316-353.

Mather, J. A., \& Anderson, R. C. (1999). Exploration, play and habituation in octopuses (Octopus dofleini). Journal of Comparative Psychology, 113, 1-6.

Mather, J. A.,\&Anderson, R. C. (2000). Octopuses are smart suckers! The cephalopod page. Retrieved June 7, 2001 from the World Wide Web: http:/manandmollusc.net/smart_suckers.html.

Matlin, W. H.,\&Foley, H. J. (1997). Sensation and perception (4th ed.). Needham Heights, MA: Allyn and Bacon.

Merskey, H. (1986). Classification of chronic pain: Description of chronic pain syndromes and definitions of pain terms. Pain Supplement, 3, S1-S226.

Olfert, E. D., Cross, B. M.,\& McWilliam, A. A. (Eds.). (1993).CCAC guide to the care and use of experimental animals: Vol. 1 (2nd ed.). Ottawa: Canadian Council of Animal Care.

Parker, S. T., Mitchell, R. W., \& Boccia, M. L. (Eds.). (1994). Self-awareness in animals and humans. Cambridge, England: Cambridge University Press.

Peterson, J. (1999). Essentials of cooking. New York: Workman.

Roll in, B. E. (1985). The moral status of research animals in psychology. American Psychologist, 40,920-926. 
Shepherdson, D. L., Mellen, J. D., \& Hutchins, M. (Eds.). (1998). Second nature: Environmental enrichment for captive animals. Washington, DC: Smithsonian Institute Press.

Wells, M. J. (1978). Octopus: Physiology and behavior of an advanced invertebrate. London: Chapman and Hall.

White, D. J.,\&Shawhan, R. (1996). Emotional responses of animal shelter workers to euthanasia. Journal of the American Veterinary Medical Association, 208, 846-849. 